\title{
Crop Classification Using Imagery of Drone
}

\author{
Jin-ki Park \\ Post Doctor, Department of Agricultural \& Rural Engineering \\ Chungbuk National University \\ 52 Chungdea-ro 1, Cheongju-si, Chungbuk 361-763, South \\ Korea
}

\begin{abstract}
Drone have several advantages over conventional remote sensing techniques. They can acquire high-resolution images quickly and repeatedly. And with a comparatively lower flight altitude i.e. $80 \sim 400 \mathrm{~m}$, they can obtain good quality images even in cloudy weather. Therefore, they are ideal for acquiring spatial data in cases of small agricultural field with mixed crop, abundant in South Korea. This study discuss the use of low cost the drone based remote sensing for classifying crops. The study area is a main producer of Chinese cabbage and radish. This study acquired image using fixed wing drone on September 23, 2014. An object-based technique is used for classification of crops. The results showed that scale 250 , shape 0.1 , color 0.9 , compactness 0.5 and smoothness 0.5 were the optimum parameter values in image segmentation. As a result, the kappa coefficient was 0.82 and the overall accuracy of classification was $84.7 \%$. The drone images taken at the appropriate time will be able to solve the difficulties of remote sensing data acquisition of agricultural area.
\end{abstract}

Keywords-component; drone; object based method; crops classifition; remote sensing

\section{INTRODUCTION}

The major advantage of remote sensing technology is that it can acquired the necessary information quickly without in-situ visits. Particular in the agricultural sector, research utilizing remote sensing technologies has been increasing. Although, low-resolution satellite images acquisition with short interval between two images is possible such as MODIS, NOAA AVHRR, etc., it is not suitable to monitor in case of small agricultural field with mixed crop, abundant in South Korea. High-resolution satellite images are not suitable for agricultural monitoring because of temporal resolution. In addition, it is difficult to acquire good quality images due to the heavy rains and typhoons during the vital period of July to September for agricultural monitoring in South Korea. The drones have several advantages over conventional remote sensing techniques. They can acquire high-resolution images quickly and repeatedly with a comparatively lower flight altitude i.e. $80 \sim 400 \mathrm{~m}$ which again help to obtain good quality images even in cloudy weather.

In recent years, fluctuation and instability of agricultural product prices has become a matter of supply and demand imbalance and distribution system in South Korea. In particular, as the demand for Chinese cabbage and radish in autumn increases considerably it has a huge influence on people's living cost. However, the two crops are produced many variations depending on weather conditions and crop planting intentions. To solve these problems, Ministry of Agriculture,

\author{
Jonghwa Park* \\ Professor, Department of Agricultural \& Rural Engineering \\ Chungbuk National University \\ 52 Chungdea-ro 1, Cheongju-si, Chungbuk 361-763, South \\ Korea \\ *Corresponding author
}

Food and Rural Affairs (MAFRA) in South Korea is trying to stabilize supply and demand through agriculture observation, contract farming. The agriculture observation is carried out mostly by field survey, and requires a lot of manpower.

The purpose of the present study is to classify crops using drone imagery and to evaluate the usability of drone based crops classification in agriculture.

\section{METHODS AND MATERIALS}

\section{A. Study Area}

The present study is conducted over Gochang-gun in South Korea which occupies the southwest portion of the Korean peninsula. It lies between latitudes $35.32^{\circ} \mathrm{N}$ and longitudes $126.55^{\circ} \mathrm{E}$ covering a total area of $2.1 \mathrm{~km}^{2}$ (Figure I). The study area is a main producer of Chinese cabbage and radish in autumn.

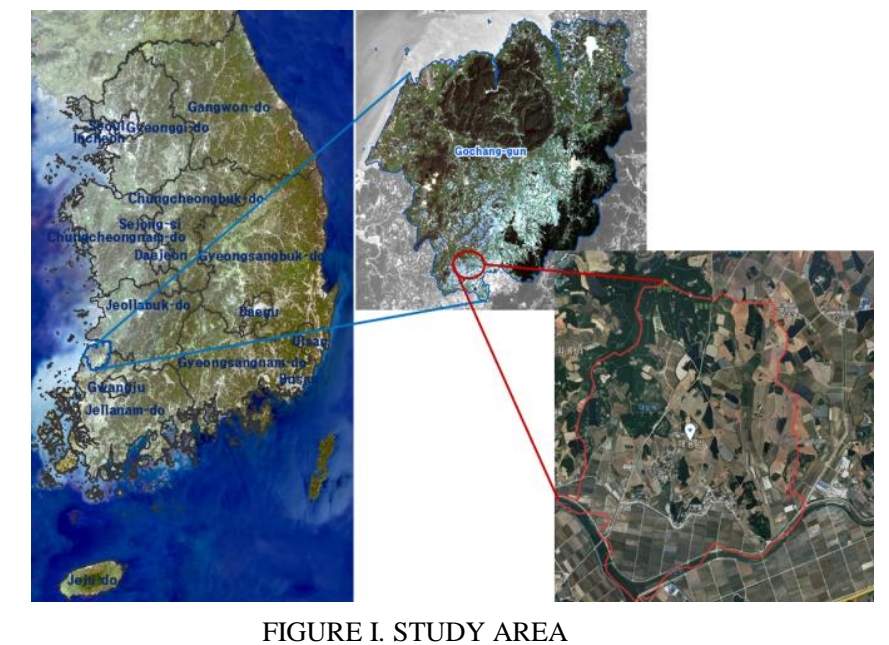

\section{B. Drone and Sensors}

In this study, fixed wing drone was used to acquire image for agricultural monitoring (Figure II). It has a $0.96 \mathrm{~m}$ wingspan and when fully loaded for flight it has a mass of $0.69 \mathrm{~kg}$, making it one of the lightest mapping drones on the market [1]. The maximum flight time is 50 minutes and when carrying out a mapping mission it cruise speed $40 \sim 90 \mathrm{~km} /$ hour while powered by a rechargeable Lithium-polymer battery. It uses Canon 16 mega pixel sensor that are capable of imaging in the visible band (Red, Green, Blue) and 12 mega pixel in Near Infra sensor (Near Infra, Red, Green). 
This study acquired images using fixed wing drone on September 23, 2014. When drone acquires images, flight plan has 9 waypoint, $18.3 \mathrm{~km}$ of total flight distance, 25 minutes of flight time, 260m (RGB sensor) and 229m (NIR sensor) of altitude from ground and $0.08 \mathrm{~m}$ of GSD (Ground Sampling Distance).

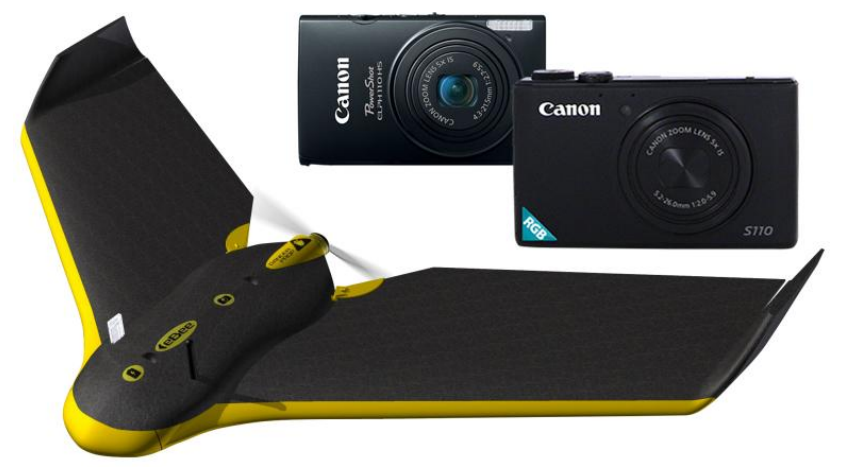

FIGURE II. FIXED WING DRONE AND SENSORS

\section{Crops Classification}

In general, a pixel-based image classification method is used during the processing of a satellite image. However, there is a problem of salt and pepper noise with the high-resolution image using pixel-based method [2]. Because of this problem, in case of classification of high-resolution images of $5 \mathrm{~m}$ or less, an object-based method is widely applied. The object-based method has an advantage of using spectral and spatial information when classifying land coverage in a highresolution image [3], [4]. This study also used object-based method for classifying image because the spatial resolution of drone image is $0.08 \mathrm{~m}$.

\section{RESULTS AND DISCUSSION}

\section{A. Data Processing}

The drone acquired 150 images from RGB sensor and 192 images from NIR sensor. The number of images from sensors is difference because of the difference in pixel number. Drone images mosaic was carried out by the Pix4D's Postflight Terra 3D program. It need GPS coordinates and pitch, roll and yaw values from drone information during flying (Figure III)[5]. The result of the drone images mosaic is shown in Figure IV and Figure V.

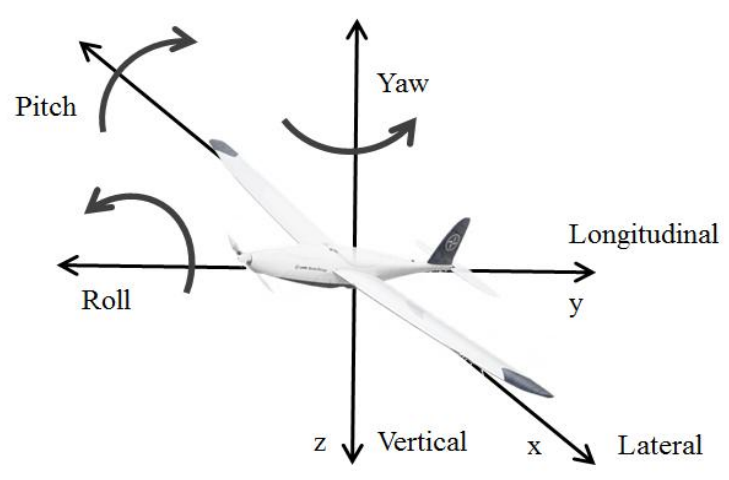

FIGURE III. PITCH, ROLL AND YAW OF DRONE

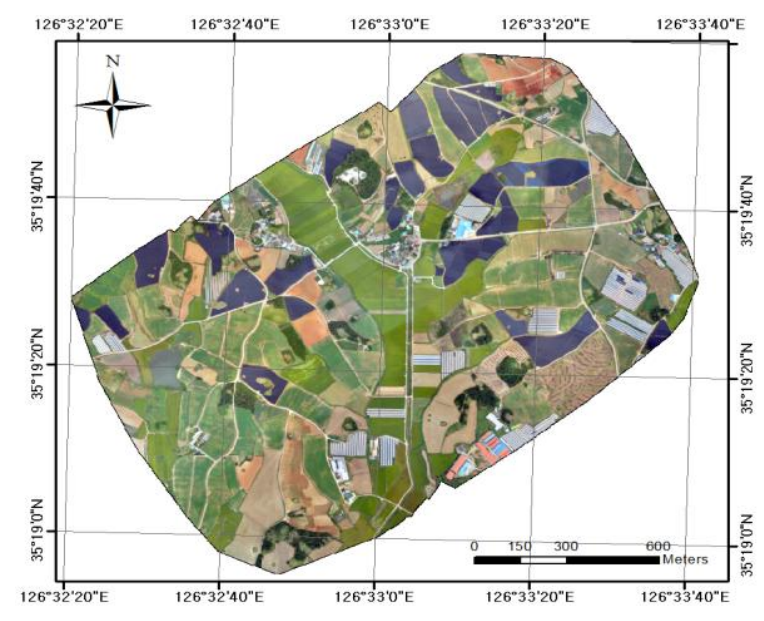

FIGURE IV. RESULT OF MOSAIC IMAGE FROM RGB

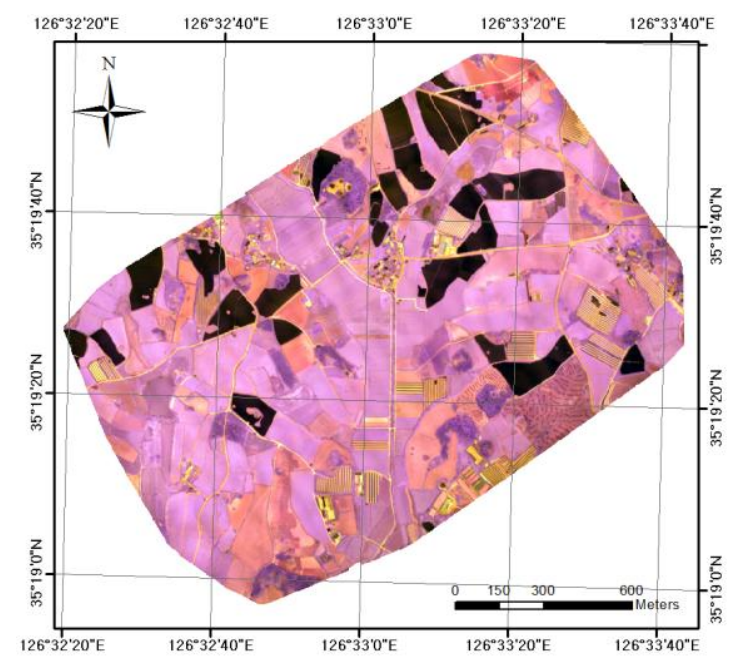

FIGURE V. RESULT OF MOSAIC IMAGE FROM NIR

\section{B. Crops Classification}

Crops classification was used for single image which consists blue, green, red and near-infrared layer. The method of trial and error is used in order to obtain optimum segmentation results. As a result, the optimum parameters of the drone image determined 250 of scale factor, 0.1 of shape, 0.9 of color, 0.5 of compactness and 0.5 of smoothness. There are some error in case of ambiguous boundary. The error is modified by checking with the naked eye, thus reducing the error in the crops classification process. The result of segmentation is shown in Figure V.

The classification of drone image was executed after processing segmentation. The drone image was classified into 11 land classes; grassland, barren, paddy, welsh onion, road, radish, Chinese cabbage, forest, ginseng, water and vinyl house. The Ministry of Environment in South Korea classify standardization into 41 land cover class for high-resolution image. But the purpose of this study is not important to classify building, house, road, etc. It was selected with 11 land classes based on the field survey for best result of crops classification. The result of image classification is shown as Figure VI. 


\section{Accuracy and Validation}

The accuracy of the classification result using the objectbased method was evaluated using the Error matrix. It was conducted by comparing the classified image and observed field survey. The classes used for verification were grassland, barren, paddy, radish, Chinese cabbage, ginseng and vinyl house except welsh onion, road, forest and water. These classes are excluded from evaluation because the split object of road and forest is very small. It is same for welsh onion and water as the number of observations is less than 10. 459 points are selected for measuring accuracy as shown in TABLE I. 389 of 459 points were found to be exactly in the same class as estimated and so the overall accuracy of classification was $84.7 \%$. And the kappa coefficient was 0.82 .

The result is high accuracy. So it is useful to classify crops using high-resolution image of drone. The drone is the equipment that solves the shortcoming in temporal resolution of satellite images. Especially, if you take the advantage of drone, the difficulty of remote sensing data acquisition in agricultural sector is solved.

\section{CONCLUSIONS}

In this study, the fixed wing drone and the object-based method was used to classify crops. The conclusions were followings.

1) Crops were classified using the object-based method. As a result of image segmentation, the optimum parameters of the drone image determined 250 of scale factor, 0.1 of shape, 0.9 of color, 0.5 of compactness and 0.5 of smoothness.

2) The drone image was classified according to the 11 land classes; grassland, barren, paddy, welsh onion, road, radish, Chinese cabbage, forest, ginseng, water and vinyl house.

3) 389 of 459 points were found to be exactly in the same class as estimated and so the overall accuracy of classification was $84.7 \%$. And the kappa coefficient was 0.82 .

4) The result of the present sudy validate our attempts for crop classification using high resolution drone image as well as established the possibility of using such remote sensing techniques widely to resolve the difficulty of remote sensing data acquisition in agricultural sector.

\section{ACKNOWLEDGMENT}

This research was supported by Basic Science Research Program through the National Research Foundation of Korea (NRF) funded by the Ministry of Science, ICT \& Future Planning (NRF-2014R1A6A3A01009541).

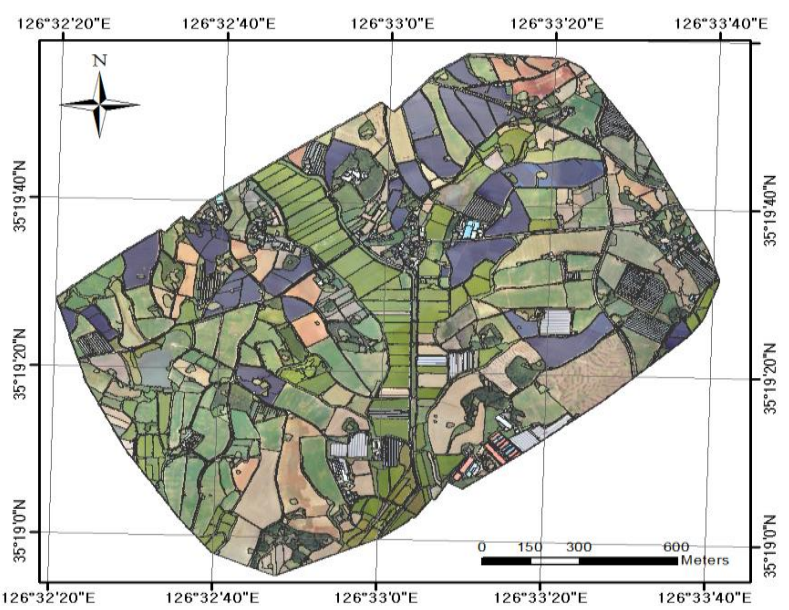

FIGURE VI. RESULT OF IMAGE SEGMENTATION

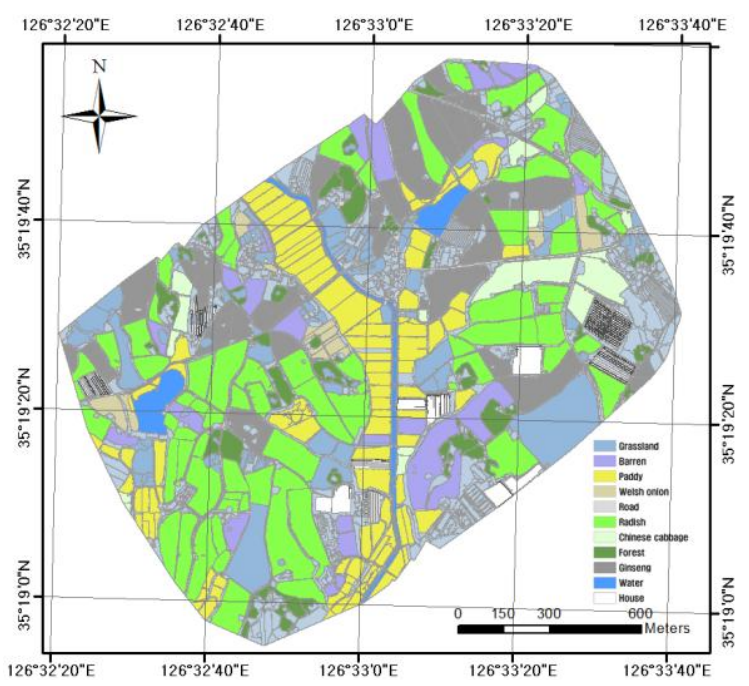

FIGURE VII. RESULT OF IMAGE CLASSIFICATION

TABLE I. REULTS OF ACCURACY ASSESSMENT

\begin{tabular}{|c|c|c|c|c|c|c|c|c|c|c|}
\hline \multirow{2}{*}{\multicolumn{2}{|c|}{ Classified data }} & \multicolumn{9}{|c|}{ UAV image } \\
\hline & & & & & & & & & & \\
\hline \multirow{9}{*}{$\begin{array}{c}\text { Field } \\
\text { survey }\end{array}$} & Grassland & 102 & 0 & 1 & 6 & 3 & 3 & 0 & 115 & 88.7 \\
\hline & Ginseng & 0 & 31 & 0 & 0 & 0 & 0 & 0 & 31 & 100.0 \\
\hline & House & 20 & 2 & 85 & 7 & 2 & 8 & 1 & 125 & 68.0 \\
\hline & Barren & 3 & 0 & 0 & 23 & 0 & 1 & 0 & 27 & 85.2 \\
\hline & Paddy & 0 & 0 & 0 & 5 & 74 & 1 & 0 & 80 & 92.5 \\
\hline & Radish & 2 & 0 & 0 & 2 & 0 & 60 & 1 & 65 & 92.3 \\
\hline & $\begin{array}{l}\text { Chinese } \\
\text { cabbage }\end{array}$ & 0 & 0 & 0 & 0 & 0 & 2 & 14 & 16 & 87.5 \\
\hline & $\begin{array}{c}\text { Column } \\
\text { total }\end{array}$ & 127 & 33 & 86 & 43 & 79 & 75 & 16 & \multirow{2}{*}{\multicolumn{2}{|c|}{$\begin{array}{c}\text { Overall } \\
\text { accuracy } \\
84.7 \%\end{array}$}} \\
\hline & $\begin{array}{c}\text { Producer's } \\
\text { accuracy }(\%)\end{array}$ & 80.3 & 93.9 & 98.8 & 53.5 & 93.7 & 80.0 & 87.5 & & \\
\hline \multicolumn{2}{|c|}{ Kappa index } & \multicolumn{9}{|c|}{0.82} \\
\hline
\end{tabular}




\section{REFERENCES}

[1] J. B. sharma, and D. Hulsey, "Intergrating the UAS in indergranduate teaching and research-opportunities and challenges at the university of North Georgia," The International Archives of the Photogrammetry, Remote Sensing and Spatial Information Sciences, vol. XL-1, 2014.

[2] S. M. de Jong, T. Hornstra, and H. G. Maas, "An integrated spatial and spectral approach to the classification of Mediterranean land cover type: the SSC method," International Journal of Applied Earth Observation and Geoinformation, vol. 3, issue 2, pp. 176-183.

[3] H. O. Kim, and J. M. Yeom, "A study on object based image analysis methods for land cover classification in agricultural area," Journal of the Korean association of geographic information studies, vol. 15, issue 4, pp. 26-41. (in Korean).

[4] S. H. Lee, Y. G. Oh, N. Y. Park, S. H. Lee and J. Y. Choi, "Extraction of paddy field in Jaeryeong, North Korea by object-oriented classification with RapidEye NDVI imagery," Journal of the Korean Society of Agricultural Engineers, vol. 56, issue 3, pp. 55-64. (In Korean).

[5] B. S. Kim, "Crop classification using unmanned aerial vehicle imagery and object-based classification method," The Master's thesis, Chungbuk National University. (In Korean). 